Bulletin of PharmaceuticalSCiences
Assiut University
e-mail: bullpharm@aun.edu.eg

\title{
DEVELOPMENT AND CHARACTERIZATION OF NANO- STRUCTURED LIPID CARRIERS FOR TRANSDERMAL DELIVERY OF MELOXICAM
}

\author{
Radwa Radwan ${ }^{1 *}$, Mahmoud El-Badry ${ }^{2}$, Gihan Fetih $^{2}$, Ayat Allam ${ }^{2}$ and Mahmoud Elsabahy ${ }^{2,3}$ \\ ${ }^{1}$ Assiut International Center of Nanomedicine, Al-Rajhy Liver Hospital, Assiut University, \\ Assiut, Egypt \\ ${ }^{2}$ Department of Pharmaceutics, Faculty of Pharmacy, Assiut University, Assiut, Egypt \\ ${ }^{3}$ Department of Chemistry, Laboratory for Synthetic-Biologic Interactions,Texas A\&M \\ University, College Station, TX, USA
}

\begin{abstract}
For transdermal delivery of meloxicam, nanostructured lipid carriers containing compritol as solid lipid, oleic acid as liquid lipid and different ratios of Pluronic F-68 were prepared. The prepared nanoparticles were characterized in terms of size, polydispersity index, zeta-potential and encapsulation efficiency. The average particle size, zeta-potential and encapsulation efficiency ranged from 134 to $491 \mathrm{~nm}$, from -12.4 to $-23.23 \mathrm{mV}$ and from 35 to $70 \%$, respectively. Furthermore, in vitro release for a number of selected formulations was performed using dialysis membrane in phosphate buffer saline. Drug release from free solution compared to release from nanostructured lipid carriers over a period of 48 hours was evaluated as well as release kinetic analysis was investigated. Moreover, stability of the selected formulation was studied at different time intervals. In addition, meloxicam-loaded nanostructured lipid carriers gel containing Carbopol-934 as a gelling agent was prepared. Moreover, anti-inflammatory activity of the prepared gel was evaluated using carrageenan-induced rat paw edema method. Meloxicamloaded nanostructured lipid carriers gel showed a more sustained inhibitory effect compared to free meloxicam gel. Finally, toxicity of the prepared meloxicam-loaded nanostructured lipid carriers gel was evaluated using histopathological examination.
\end{abstract}

\section{INTRODUCTION}

Meloxicam (MLX) is a water insoluble, potent, nonsteroidal, anti-inflammatory drug (NSAIDs) $^{1}$. It selectively inhibits cyclooxygenase- $2(\mathrm{COX}-2)^{2}$. It is commonly used in the symptomatic treatment of joint disorders like rheumatoid arthritis and osteoarthritis ${ }^{384}$. It is conventially marketed as tablets. However, its oral administration associated with some gastrointestinal side effects ${ }^{5 \& 6}$. Transdermal delivery of meloxicam would eliminate gastrointestinal irritation and avoid first pass metabolism? ${ }^{7}$. But unfortunately, it has low aqueous solubility, poor skin penetration and also low incorporation into formulations ${ }^{8 \& 9}$. Moreover, transdermal delivery of meloxicam still challenging due to presence of outer most layer of skin (stratum corneum) which act as a barrier against delivery of many drugs ${ }^{10}$. Recently, attention has been focused on solid lipid nanoparticles (SLNs) and nanostructured lipid carriers (NLCs) for the transdermal delivery of many drugs ${ }^{11-13}$. Both SLNs and NLCs offer many advantages for the transdermal delivery of many drugs ${ }^{14 \& 15}$. As they exhibit small sizes that ensure a good contact with skin and thus enhance drug permeation through skin, also improve encapsulation of lipophilic drugs and control the release of many other drugs ${ }^{16-18}$. Moreover, lipid nanoparticles offer stability of drugs that are either sensitive to light or chemically unstable $^{19 \& 20}$. However, SLNs have some

Received in 28/10/2019 \& Accepted in 6/11/2019 
limitations as drug expulsion during storage and low drug loading capacity ${ }^{18}$. Recently, an attention has been paid to the formulation of NLCs that considered a second generation of lipid nanoparticles. NLCs have been developed by replacing amount of solid lipid by liquid one which lead to imperfect structure, and, thus increasing the amount of incorporated drug, and avoiding drug leakages that occur with SLNs during storage ${ }^{21-23}$. Moreover, NLCs have an occlusive effect, increase skin hydration and promote drug permeation through the $\operatorname{skin}^{24 \& 25}$. Furthermore, their small sizes offer higher contact with skin, and, thus higher penetration could be obtained. In addition, their components have a great influence on drug penetration ${ }^{23 \& 26}$. Furthermore, incorporation of drug into NLCs leads to drug release in a controlled manner ${ }^{26 \& 27}$. Consequently, MLX loading into NLCs would be a promising strategy for its transdermal delivery. However, NLCs dispersion is inappropriate for dermal application because of their low viscosity. Thus, NLCs conversion into gel would be advantageous for dermal application into the skin. The aim of this study is to develop and characterize NLCs for transdermal delivery of meloxicam. In this work, effect of different lipid ratios and surfactant concentrations on size, encapsulation efficiency and in vitro release of NLCs have been studied. Moreover, in-vivo anti-inflammatory effect of MLXloaded NLCs gel has been evaluated.

\section{MATERIALS AND METHODS}

\section{Materials}

Meloxicam was obtained as a gift from Medical Union Pharmaceuticals (Abu-Sultan, Ismailia, Egypt), Compritol 888 ATO was supplied by Gattefosse' (France), oleic acid was purchased from Alpha Chemicals (Cairo, Egypt), Pluronic F-68 was provided by BASF (Luwigshafen, Germany), dialysis membrane (molecular weight $=12000-14000 \mathrm{Da})$ and Carpobol-934 was purchased from Fluka Chemica (Buchs, Switzerland).

\section{Methods}

Nanostructured lipid carriers were prepared by melt emulsification followed by ultrasonication as per the reported methods with slight modification ${ }^{28 \& 29}$. Shortly, the lipid phase, composed of compritol as solid lipid and oleic acid as liquid lipid at different ratios, as mentioned in table 1 and 2, was heated to 5$10^{\circ} \mathrm{C}$ above melting point of Compritol. MLX $(10 \mathrm{mg})$ was dissolved in the melted lipid. An aqueous phase containing Pluronic F-68 was heated up to the same temperature of the melted lipids. Then, hot aqueous phase was added to drug-lipid mixture and stirred for 5 min at $4000 \mathrm{rpm}$ to obtain $\mathrm{O} / \mathrm{W}$ emulsion. After that, the obtained $\mathrm{O} / \mathrm{W}$ emulsion was further subjected to sonication using ultrasonicator (Cole-Parmer, Vernon Hills, IL) $(50 \% \mathrm{~W}, 5$ min, 2 on $\& 2$ off) to obtain nanoemulsion.

Table 1: Composition of the developed MLX nanostructured lipid carriers with different drug: lipid ratios and Compritol amounts.

\begin{tabular}{|c|c|c|c|c|c|}
\hline \hline Formulation & $\begin{array}{c}\text { MLX } \\
(\mathrm{mg})\end{array}$ & $\begin{array}{c}\text { Drug: Lipid } \\
\text { ratio }\end{array}$ & $\begin{array}{c}\text { Pluronic F-68 } \\
(\mathrm{mg})\end{array}$ & $\begin{array}{c}\text { Compritol } \\
(\mathrm{mg})\end{array}$ & $\begin{array}{c}\text { Oleic acid } \\
(\mathrm{mg})\end{array}$ \\
\hline F1 & 10 & $1: 15$ & 112.5 & 105.0 & 45.00 \\
\hline F2 & 10 & $1: 20$ & 150.0 & 140.0 & 60.00 \\
\hline F3 & 10 & $1: 30$ & 225.0 & 210.0 & 90.00 \\
\hline F4 & 10 & $1: 15$ & 112.5 & 82.50 & 67.50 \\
\hline F5 & 10 & $1: 20$ & 150.0 & 110.0 & 90.00 \\
\hline F6 & 10 & $1: 30$ & 225.0 & 165.0 & 135.0 \\
\hline F7 & 10 & $1: 15$ & 112.5 & 45.00 & 105.0 \\
\hline F8 & 10 & $1: 20$ & 150.0 & 60.00 & 140.0 \\
\hline F9 & 10 & $1: 30$ & 225.0 & 90.00 & 210.0 \\
\hline \hline
\end{tabular}


Table 2: Composition of the developed MLX-NLCs with different Pluronic (PF-68) amounts (mg).

\begin{tabular}{||c|c|c|c|c|c||}
\hline \hline Formulation & $\begin{array}{c}\text { MLX } \\
(\mathrm{mg})\end{array}$ & $\begin{array}{c}\text { Drug: Lipid } \\
\text { ratio }\end{array}$ & $\begin{array}{c}\text { Pluronic F-68 } \\
(\mathrm{mg})\end{array}$ & $\begin{array}{c}\text { Compritol } \\
(\mathrm{mg})\end{array}$ & $\begin{array}{c}\text { Oleic acid } \\
(\mathrm{mg})\end{array}$ \\
\hline F1 & 10 & $1: 15$ & 112.5 & 45.00 & 105.0 \\
\hline F2 & 10 & $1: 15$ & 150.0 & 45.00 & 105.0 \\
\hline F3 & 10 & $1: 15$ & 225.0 & 45.00 & 105.0 \\
\hline F4 & 10 & $1: 20$ & 112.5 & 60.00 & 140.0 \\
\hline F5 & 10 & $1: 20$ & 150.0 & 60.00 & 140.0 \\
\hline F6 & 10 & $1: 20$ & 225.0 & 60.00 & 140.0 \\
\hline F7 & 10 & $1: 30$ & 112.5 & 90.00 & 210.0 \\
\hline F8 & 10 & $1: 30$ & 150.0 & 90.00 & 210.0 \\
\hline F9 & 10 & $1: 30$ & 225.0 & 90.00 & 210.0 \\
\hline \hline
\end{tabular}

Measurement of particle size of MLXloaded NLCs

Average hydrodynamic diameters and Polydispersity index (PDI) were measured using a Zetasizer Nano ZS instrument (Malvern Instruments, Worcestershire, UK) equipped with a back scattered light detector operating at $137^{\circ}$. The Zeta-potential values were measured by laser doppler anemometry using Malvern zetasizer nanoseries. All samples were diluted in distilled water and all measurements were performed in triplicate at $25^{\circ} \mathrm{C}^{30}$.

\section{Determination of encapsulation efficiency (E.E)}

MLX-loaded NLCs were separated from free MLX by using cellulose acetate dialysis bag (molecular weight cut off $=12000-14000$ Da). Encapsulation efficiency of MLX-NLCs was determined spectrophotometrically at 362 $\mathrm{nm}$ using double beam spectrophotometer ${ }^{31}$.

Encapsulation efficiency (E.E) was expressed as the amount of drug encapsulated which divided by the initial amount of drug:

Encapsulation efficiency (\%) $=\frac{\text { amoum of dus encepsylated in nanopartices }}{\text { amount of dug initially added }} \times 100$ Eq. 1

\section{In-vitro release study}

In-vitro release from different NLCs and drug solution was evaluated using cellulose acetate dialysis bag diffusion technique (molecular weight cut off $=12000-14000 \mathrm{Da}$ ). MLX-NLCs were placed into dialysis bag and sealed at both ends. Then, it was immersed in a beaker containing PBS $(\mathrm{PH}=7.4)$ that was kept in a thermostatic shaker (Gesellschaft für Labortechnik mbH, Burgwedel, Germany) at $100 \mathrm{rpm}$ and maintained at $37^{\circ} \mathrm{C}$. Samples were taken at predetermined time intervals $(0.5,1,2$, $3,4,5,6,8,24$ and $48 \mathrm{hrs}$ ) and replaced by an equivalent volume of fresh medium to maintain constant volume. The release studies were performed in triplicate. The samples were subsequently analyzed spectrophotometrically at $362 \mathrm{~nm}$. Finally, the data were applied into different kinetic models as zero order, first order, Higuchi and Korsemeyer-Peppas model $^{32 \& 33}$.

\section{Stability studies}

The stability of the selected formulation (F8c) was evaluated at room temperature at different time intervals for change in size $(\mathrm{nm})$, PDI, Zeta-potential (mV) and E.E (\%).

\section{Transmission electron microscopy (TEM)}

The morphological examination of NLCs was performed with transmission electron microscopy (TEM) (JEM 100 CX11, Japan). Samples were prepared by placing a drop onto a 400-mesh copper grid coated with a carbon film, and left for air drying.

TEM images were then observed at an acceleration voltage of $80 \mathrm{kV}$.

\section{Fourier transform-Infrared spectroscopy}

Nanostructured lipid carriers were lyophilized to obtain dry product. The selected formulation (F8c) was frozen at $-80^{\circ} \mathrm{C}$ overnight prior to the lyophilization process. Then, transferred to Alpha 2-4 LD plus freezedryer (Martin Christ GmbH, Osterode, Germany) for $24 \mathrm{hrs}$. The FT-IR spectrum was performed for MLX-loaded NLCs, free drug and Compritol using FT-IR spectrophotometer (IR-470; Shimadzu, Kyoto, Japan). Samples were mixed with potassium bromide 
(spectroscopic grade), compressed into disks and scanning was performed from 4000 to 500 $\mathrm{cm}^{-1}$.

\section{Differential scanning calorimetry}

The thermal behaviors of free drug, Compritol and selected formulation (F8c) were investigated by differential scanning calorimetry (DSC- 60; Shimadzu Corporation, Tokyo, Japan). Samples were sealed in aluminum pans and heated over a temperature range of $50-350^{\circ} \mathrm{C}$ at a constant rate of $10^{\circ} \mathrm{C} / \mathrm{min}$. Thermal analysis data were recorded using a TA 50I PC system with Shimadzu software programs. Indium standard was used to calibrate the DSC temperature and enthalpy scale. N2 was used as purging gas at a rate of $50 \mathrm{~mL} / \mathrm{min}$. An empty sealed aluminum pan was used as a reference.

\section{Preparation of MLX and MLX-NLCs gels}

Selected MLX-NLC and MLX gel were prepared according to the following method. Carbopol 934 (2\%) was dispersed in alcoholic solution of MLX and MLX-loaded NLCs formulation (F8c) and mixed gently. Then, few drops of triethanolamine were added to promote gelation $^{34}$.

\section{In-vivo anti-inflammatory effects}

Carrageenan-induced rat paw edema method was used in this study to evaluate antiinflammatory effect ${ }^{35 \& 36}$. The experiment was performed according to animal ethics guidelines of Assiut University, Egypt. Adult female wistar rats weighing about $200 \mathrm{~g}$ were divided into three groups each containing five rats. The animals of group 1 received carrageenan only. Group 2 and group 3 received free MLX gel and MLX-loaded NLC gel, respectively. All rats were housed together under standard laboratory conditions with free access to food and water. Edema was induced by the sub-plantar injection of $0.5 \mathrm{ml}$ of $1.5 \%$ carrageenan solution into the left hind-paw. After $30 \mathrm{~min}$. from carrageenan injection, gel was applied to all groups except group 1 which served as a control. Measurements of paw volume were evaluated using Caliper before carrageenan injection and after injection at different time intervals $(0,2,3,4,6$ and 8$)$. The data were recorded as mean $\pm \operatorname{SD}(n=5)$.
The percent reduction of edema was calculated as follow:

$\%$ Reduction in edema $=\frac{V_{i}-V}{V_{i}}$

Eq. 2

V: paw thickness at each time interval.

Vi: initial paw thickness.

\section{Histopathological analysis}

The study was approved by the Animal Ethics Committee. Adult female wistar rats weighing about $200 \mathrm{~g}$ were divided into two groups each containing five rats. Selected formulation was applied to the left hind paws of rats in group 2 three times daily for 1 week. Group 1 represents control group for comparison. Sections were cut and stained with haematoxylin and eosin (HE) examination by light microscopy.

\section{Statistical analysis}

The statistical analysis of data was carried out using both one-way analysis of variance (ANOVA) and student's t-test. A difference of $p<0.05$ was considered to be statistically significant.

\section{RESULTS AND DISCUSSION}

\section{Particle size, PDI and encapsulation efficiency}

MLX-NLCs were prepared via melt emulsification followed by ultrasonication. The effects of different drug: lipid ratios, oleic acidto-compritol ratios and Pluronic F-68 concentrations on size, PDI, entrapment efficiency and zeta-potential of NLCs were evaluated for further optimization of the formulations (Tables 3\&4). Different formulations were prepared using different drug: lipid ratios $(1: 15,1: 20,1: 30)$ and different oleic acid-to-compritol ratios (30 $w t . \%$ of oleic acid/total lipid), coded as F1, F2, F3, (45 wt.\% of oleic acid/total lipid), coded as F4, F5, F6 and (70 wt.\% of oleic acid/total lipid), coded as F7, F8, F9, as shown in table 3. However, drug amount and surfactant: lipid ratio (1:20) are constants. It was observed that there is a significant difference $(p<0.05)$ in size and PDI between all formulations. The results showed that oleic acid \% has a significant effect on size, PDI and E.E of NLCs. As, there was a marked decrease in 
average particle size and PDI of NLCs by increase $\%$ of oleic acid from 30 to $70 \%{ }^{30,37 \& 38}$. Size of nanoparticles was between $152.4 \pm 5.1$ and 491.0 \pm 42.6 . Minimum size, PDI and E.E were observed with minimum $\%$ of Compritol (30) and highest oleic acid \% (70). It also was found that in all formulations containing $70 \%$ oleic acid, increasing drug:lipid ratio from 1:15 to $1: 30$ resulted in increasing particle size and PDI (more heterogeneous formulations).

The average Zeta-potential was in the range of $-23.23 \pm 1.4$ to $-12.4 \pm 0.21 \mathrm{mV}$ which indicates good stability of the prepared NLCs. As shown in table 3, there was no trend for Zeta potential changes by changing drug: lipid ratios and percentage of oleic acid as reported previously $^{37}$.

Table 3: Characteristics of the developed MLX -NLCs (particle size (nm), PDI, E.E (\%) and Zetapotential $(\mathrm{mV})$.

\begin{tabular}{|c|c|c|c|c||}
\hline Formulation & $\begin{array}{c}\text { Average } \\
\text { size }(\mathrm{nm}) \pm \mathrm{SD}\end{array}$ & $\begin{array}{c}\text { Average } \\
\text { PDI } \pm \mathrm{SD}\end{array}$ & $\begin{array}{c}\text { Encapsulation } \\
\text { Efficiency } \\
(\%)\end{array}$ & $\begin{array}{c}\text { Zeta-Potential } \\
(\mathrm{mV}) \pm \mathrm{SD}\end{array}$ \\
\hline F1 & $470.3 \pm 20.3$ & $0.86 \pm 0.11$ & $45.1 \pm 0.75$ & $-23.23 \pm 1.4$ \\
\hline F2 & $491.0 \pm 42.6$ & $1.00 \pm 0.0$ & $59.9 \pm 1.70$ & $-13.23 \pm 0.52$ \\
\hline F3 & $436.0 \pm 9.2$ & $0.93 \pm 0.05$ & $50.1 \pm 2.50$ & $-21.47 \pm 0.21$ \\
\hline F4 & $357.3 \pm 25.8$ & $0.73 \pm 0.03$ & $47.1 \pm 2.99$ & $-19.57 \pm 0.68$ \\
\hline F5 & $271.3 \pm 5.5$ & $0.77 \pm 0.10$ & $69.9 \pm 0.99$ & $-20.73 \pm 0.61$ \\
\hline F6 & $330.9 \pm 37.1$ & $0.75 \pm 0.07$ & $49.9 \pm 2.6$ & $-20.93 \pm 0.33$ \\
\hline F7 & $152.4 \pm 5.1$ & $0.49 \pm 0.02$ & $45.1 \pm 1.55$ & $-17.5 \pm 0.44$ \\
\hline F8 & $178.6 \pm 1.2$ & $0.60 \pm 0.10$ & $34.9 \pm 1.79$ & $-13.43 \pm 0.26$ \\
\hline F9 & $211.7 \pm 10.7$ & $0.55 \pm 0.07$ & $34.9 \pm 2.90$ & $-20.93 \pm 0.33$ \\
\hline
\end{tabular}

Note: PDI, polydispersity index; EE, encapsulation efficiency.

Each value represents the mean \pm SD.

Table 4: Characteristics of the developed MLX -NLCs (particle size (nm), PDI, E.E (\%) and Zetapotential $(\mathrm{mV})$.

\begin{tabular}{|c|c|c|c|c||}
\hline Formulation & $\begin{array}{c}\text { Average size } \\
(\mathrm{nm}) \pm \mathrm{SD}\end{array}$ & $\begin{array}{c}\text { Average } \\
\text { PDI } \pm \mathrm{SD}\end{array}$ & $\begin{array}{c}\text { Encapsulation } \\
\text { efficiency } \\
(\%)\end{array}$ & $\begin{array}{c}\text { Zeta-Potential } \\
(\mathrm{mV})\end{array}$ \\
\hline F7a & $152.4 \pm 5.1$ & $0.49 \pm 0.02$ & $45.1 \pm 1.55$ & $-17.5 \pm 0.44$ \\
\hline F7b & $178.5 \pm 2.1$ & $0.56 \pm 0.02$ & $38.93 \pm 2.68$ & $-20.0 \pm 0.53$ \\
\hline F7c & $183.1 \pm 9.3$ & $0.62 \pm 0.04$ & $44.0 \pm 1.87$ & $-19.8 \pm 0.37$ \\
\hline F8a & $168.8 \pm 6.4$ & $0.59 \pm 0.03$ & $49.89 \pm 2.30$ & $-12.4 \pm 0.21$ \\
\hline F8b & $178.6 \pm 1.2$ & $0.60 \pm 0.10$ & $34.9 \pm 1.79$ & $-13.43 \pm 0.26$ \\
\hline F8c & $201.6 \pm 5.3$ & $0.65 \pm 0.04$ & $60.0 \pm 1.69$ & $-19.57 \pm 0.62$ \\
\hline F9a & $134.4 \pm 1.7$ & $0.46 \pm 0.08$ & $50.0 \pm 2.40$ & $-15.9 \pm 1.07$ \\
\hline F9b & $154.7 \pm 3.1$ & $0.55 \pm 0.04$ & $42.1 \pm 1.60$ & $-19.57 \pm 0.24$ \\
\hline F9c & $211.7 \pm 10.7$ & $0.55 \pm 0.07$ & $34.9 \pm 2.90$ & $-20.93 \pm 0.33$ \\
\hline \hline
\end{tabular}

Note: PDI, polydispersity index; EE, encapsulation efficiency.

Each value represents the mean \pm SD. 
From table 3, it was observed that optimal results of size, PDI and E.E obtained with highest $\%$ of oleic acid (70\%). On the other hand, different formulations were prepared with different concentrations of PF-68 $(0.75 \%$ $w / v)$, coded as F7a, F8a, F9a, (1\% $w / v)$, coded as F7b, F8b, F9b and $(1.5 \% w / v)$ coded as F7c, F8c, F9c while maintaining drug: lipid ratios and oleic acid-to-compritol ratios constant. $t$ was observed that there is a significant difference between particle size and PDI ( $p<$ $0.05)$. As size and PDI increased by increasing concentration of Pluronic F-68. The resultant increase in size of NLCs upon increase surfactant concentration might be due to accumulation of surfactant molecules on the surface owing to hydrophobic interaction between nonpolar alkyl chain of surfactant and solid lipid molecules ${ }^{39 \& 40}$. When drug: lipid ratio was 1:30; it also was observed that increasing pluronic F-68 concentration resulted in decrease encapsulation efficiency and this may be attributed to partitioning of drug more toward aqueous phase. As shown in table 4, zeta-potential values were in the range of -12.4 \pm 0.21 to $-20.93 \pm 0.33 \mathrm{mV}$ and this also as mentioned previously is a sign of good stability. It was observed that there was an increase in zeta potential values upon increasing surfactant concentration.

\section{In-vitro release study from drug solution and NLCs}

Figures $1 \& 2$ show drug release profile from its solution and from different NLCs. Drug released from NLCs in a biphasic manner as it was observed that rapid drug release obtained in the first followed by a sustained release. Figure 1 demonstrates effect of oleic acid $\%$ on release of drug from its NLCs. Free drug solution showed a significant $(p<0.05)$ faster and higher release than from NLCs. As it showed about $23.6 \%$ release after first 30 min. However, drug release from its different NLCs ranged only from 4.13 to $8.5 \%$ after $30 \mathrm{~min}$. When release profile of MLX from its different NLCs was compared with each other after $48 \mathrm{~h}$, it was found that F2 and F5 have the highest release rate. This might be attributed to a higher concentration of surfactant (1.5\%) which facilitates drug passage toward the media. On the other hand, F5 exhibited a higher release rate as F5 contains higher percentage of oleic acid (45\%) compared to F2 $(30 \%)$. And this might be due to reduction in the crystallinity of nanoparticles and hence more imperfect crystals formation upon increasing oleic acid permeating more amount of drug to be released into the media ${ }^{37}$.

Figure 2 illustrates the effect of different surfactant concentration on release profile. Also here MLX solution exhibited higher drug release compared to other MLX- NLCs. MLX solution showed $23.06 \%$ release after $30 \mathrm{~min}$. However, MLX-NLCs exhibited only 4.139.7\% release. It was found that F8c showed the highest percentage of MLX release after 48h.This might be referred to the high surfactant concentration $(1.5 \%)$ that increase leakage of drug from NLCs. However, F7a and F9a exhibited slower release compared to F8c as they contain lower surfactant concentration $(0.75 \%)$.

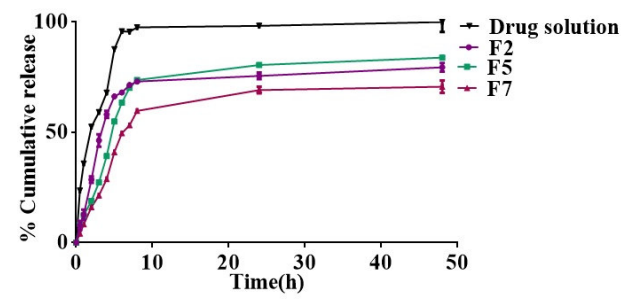

Fig. 1: In-vitro release profile of MLX from its NLCs (F2, F5, F7).

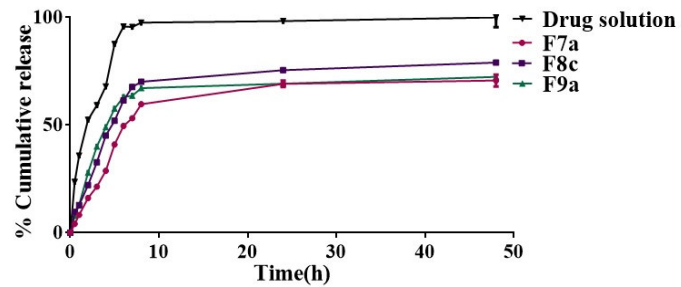

Fig. 2: In-vitro release profile of MLX from its NLC (F7a, F8c, F9a).

At the end, kinetic analysis was performed and the resulted correlation coefficients $\left(R^{2}\right)$ were calculated and listed in table 5. All formulations showed that drug released through a diffusion mechanism (i.e. Higuchi equation). Moreover, Korsemeyer-Peppas model was applied to ensure mechanism of drug release. All formulations were found to have diffusion exponent $\leq 0.5$ meaning that drug release followed controlled by fickian diffusion. 


\section{Stability studies}

Table 6 shows that there is no significant $(p>0.05)$ change in size of nanoparticles after 1 month from storage at room temperature. Similarly, there was a non-significant change in zeta-potential of nanoparticles after 3 weeks.
However, a significant decrease $(p=0.01)$ was observed after 4 weeks. Finally, MLX- loaded NLCs was screened for the stability of encapsulated drug and it exhibited good results as there was no significant difference in E.E \% after 1 month.

Table 5: Release kinetics of MLX-loaded NLCs using various equations.

\begin{tabular}{||c|c|c|c|c||}
\hline \multirow{2}{*}{ Formulation } & \multicolumn{4}{|c|}{ Correlation coefficient $\left(\mathrm{R}^{2}\right)$} \\
\cline { 2 - 5 } & Zero order & First order & Higuchi model & $\begin{array}{c}\text { Korsmeyer-Peppas } \\
\text { (n) }\end{array}$ \\
\hline F2 & 0.9346 & 0.9713 & 0.9726 & 0.4001 \\
\hline F5 & 0.9893 & 0.9894 & 0.9895 & 0.5183 \\
\hline F7 & 0.9913 & 0.9900 & 0.9929 & 0.4957 \\
\hline F8c & 0.7175 & 0.7922 & 0.8491 & 0.4627 \\
\hline F9a & 0.9570 & 0.9825 & 0.9865 & 0.3958 \\
\hline
\end{tabular}

Table 6: Physicochemical characteristics of the optimized formulation (F8c) at different time intervals.

\begin{tabular}{||c|c|c|c|c||}
\hline Parameter & 1 Week & 2 weeks & 3 weeks & 4 weeks \\
\hline Average size $(\mathrm{nm}) \pm \mathrm{SD}$ & $209.8 \pm 5.88$ & $198.9 \pm 6.1$ & $229.5 \pm 3.77$ & $287.8 \pm 58.35$ \\
\hline Average PDI \pm SD & $0.59 \pm 0.02$ & $0.57 \pm 0.04$ & $0.54 \pm 0.01$ & $0.5 \pm 0.05$ \\
\hline Average Zeta-potential $(\mathrm{mV}) \pm$ SD & $-20.3 \pm 0.4$ & $-18.6 \pm 1.14$ & $-19.8 \pm 0.35$ & $-17.9 \pm 0.15$ \\
\hline Average E.E $(\%) \pm$ SD & $59.8 \pm 1.2$ & $59.1 \pm 0.08$ & $58.45 \pm 2.4$ & $57.98 \pm 2.8$ \\
\hline
\end{tabular}

\section{Transmission electron microscopy (TEM)}

The morphological examination was shown in figure 3 . The selected formulation of MLX-loaded NLCs exhibited morphological shape. It showed no aggregation a narrow size distribution.



Fig. 3: Morphological examination of MLX-loaded NLCs using TEM.

Fourier transform-infrared spectroscopy

Structural composition of pure MLX, MLX-loaded NLCs and compritol was performed using fourier transform-infrared spectroscopy. Their FT-IR spectra are shown in figure 4. Pure MLX has major absorption peaks at 3290, 1620, 1530 and $1160 \mathrm{~cm}^{-}$ ${ }^{1}$, corresponding to secondary amine stretch, C$\mathrm{H}$ stretch aromatic, $\mathrm{C}=\mathrm{N}$ stretch and $\mathrm{S}=\mathrm{O}$ stretch, respectively. Compritol shows absorption bands at 2910 and $2840 \mathrm{~cm}^{-1}$ due to $\mathrm{C}-\mathrm{H}$ stretching. Moreover, it shows absorption bands at $1730 \mathrm{~cm}^{-1}$ due to $\mathrm{C}=\mathrm{O}$ stretching. Spectrum of MLX-loaded NLCs showed absence of MLX characteristic peaks and this might be attributed to incorporation of drug in the lipid matrix.

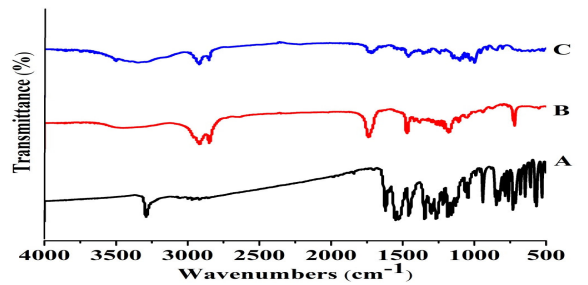

Fig. 4: Fourier transform Infrared spectroscopy of (A) MLX, (B) Compritol, (C) MLX-loaded NLCs. 


\section{Differential scanning calorimetry}

Figure 5 shows the thermogram of Compritol, MLX and the optimized formulation of MLX-loaded NLCs. It was found that MLX and core lipid Compritol exhibited sharp endothermic peaks at 263.4 and $79.6^{\circ} \mathrm{C}$, respectively. As shown in figure 5, lyophilized MLX-loaded NLCs didn't exhibit the sharp endothermic peak of MLX. This shows that MLX transformed from the crystalline to amorphous phase. In contrast, it was observed that the melting point of compritol was shifted to higher values (from 79.6 to $95.94^{\circ} \mathrm{C}$ ). This might be due to presence of surfactant and nanosized formulation.



Fig. 5: DSC thermogram of (A) MLX, (B) Compritol and (C) MLX-loaded NLCs.

\section{Preparation of MLX and MLX-NLCs gels}

For ease of topical application, free MLX and MLX-loaded NLCs gel were prepared. After screening all formulations, it was found that F8c has small particle size $(201.6 \pm 5.3 \mathrm{~nm})$ and good stability over a period of 1 month. Consequently, F8c (containing 70\% oleic acid and $30 \%$ Compritol was selected to prepare a more convenient formulation for the topical administration.

\section{In-vivo anti-inflammatory effects using paw edema}

The anti-inflammatory effect of the prepared MLX-loaded NLCs gel was evaluated using paw edema test. Biological evaluation was performed after topical application of MLX-loaded NLCs gel and free MLX gel and comparing volume of edema to the control group. Figure 6 demonstrates antiinflammatory activity of MLX gel and MLXloaded NLC gel on hind paw of carrageenan induced edema rat. It was found that free MLX and MLX-loaded NLC gel showed a significantly different anti-inflammatory effect compared to control group ( $p<0.05)$. MLX loaded NLC gel exhibited a more sustained action than free one. As after $2 \mathrm{hr}$ it inhibited edema by $18 \%$ and this inhibitory effect increased gradually to reach maximum (40\%) after $8 \mathrm{hr}$. However, after $8 \mathrm{hrs}$ from free MLX gel application, edema inhibited by $2 \%$. Although \% inhibition after the first $2 \mathrm{hrs}$ from free MLX gel application was 30\%. And this might be attributed to that NLCs offer higher deposition and penetration of MLX through skin layers.

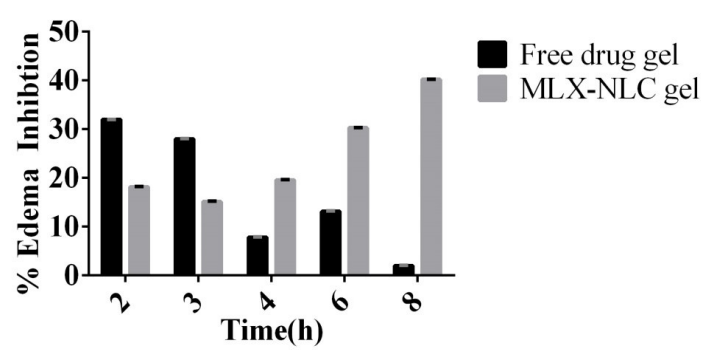

Fig. 6: Anti-inflammatory effect of free MLX gel and MLX-loaded NLC gel in carrageenan induced rat paw. Each value represents mean $\pm S D$ ( $n=5$ /group).

\section{Histopathological analysis}

Histopathological analysis was performed to investigate the safety and acceptability of MLX-loaded NLCs for topical adminstration. The histopathology of untreated rat skin and skin treated with MLX-loaded NLCs gel was shown in figure 7 . The results exhibited that control group has a normal skin which is stained with haematoxylin and Eosin (H\&E) consists of stratum corneum, stratum spinosum cells and dermis as shown in A. Moreover, Skin of control group was stained with Masson's trichome showing normal skin consist of epidermis and connective tissue with collagen with multiple hair follicles as exhibited in C. Also, after examination skin of treated group that was stained with $H \& E$ and Masson's trichome as shown in $\mathbf{B \& D}$, it was found that there is no change in histopathology from normal one. 


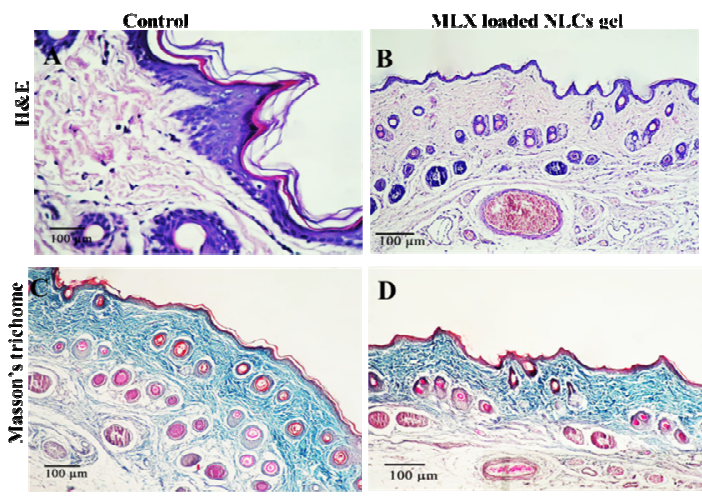

Fig. 7: Photomicrograph of skin rat for control group (A\&C) and MLX-loaded NLCs gel treated group $(\mathrm{B} \& \mathrm{D})$.

\section{Conclusion}

In conclusion, MLX-loaded NLCs were successfully prepared and characterized well. The ratio of solid lipid: liquid one and surfactant concentration have a significant impact on size of the nanoparticles and homogeneity of the formulation. Moreover, they affect release of drug that consequently affects skin permeation, deposition and also anti-inflammatory activity. The obtained results proved that NLCs could act as safe potential carriers for effective transdermal delivery of meloxicam.

\section{REFERENCES}

1- G. Engelhardt, D. Homma, K. Schlegel, R. Utzmann and C. Schnitzler, "Antiinflammatory, analgesic, antipyretic and related properties of meloxicam, a new non-steroidal anti-inflammatory agent with favourable gastrointestinal tolerance", Inflamm. Res., 44, 423-433 (1995). doi:10.1007/BF01757699.

2- I. Villegas, C. A. De la Lastra, C. La Casa, V. Motilva and M. J. Martín, "Effects of food intake and oxidative stress on intestinal lesions caused by meloxicam and piroxicam in rats", Eur. J. Pharmacol., 414, 79-86 (2001). doi:10.1016/S0014-2999(00)00883-9.

3- F. Degner, R. Sigmund and H. Zeidler, "Efficacy and tolerability of meloxicam in an observational, controlled cohort study in patients with rheumatic disease", Clin. Ther., 22, 400-410 (2000). doi:10.1016/ S0149-2918(00)89009-8.
4- J. S. Chang, Y. Bin Huang, S. Sen Hou, R. J. Wang, P. C. Wu and Y. H. Tsai, "Formulation optimization of meloxicam sodium gel using response surface methodology", Int. J. Pharm., 338, 48-54 (2007).doi:10.1016/j.ijpharm.2007.01.033.

5- S. F. Lanes, L. A. García Rodríguez and E. Hwang, "Baseline risk of gastrointestinal disorders among new users of meloxicam, ibuprofen, diclofenac, naproxen and indomethacin", Pharmaco. Epidemiol. Drug Saf., 9, 113-117 (2000). doi:10.1002 /(SICI)1099-1557(200003/04)9:2<113:: AID-PDS478>3.0.CO;2-2.

6- M. Distel, C. Mueller, E. Bluhmki and J. Fries, "Safety of Meloxicam: A Global Analysis of Clinical Trials", Rheumatology, 35, 68-77 (2012). doi:10.1093/rheumatology/35.suppl_1.68.

7- Y. Yuan, S. ming Li, F. kui Mo and D. fang Zhong, "Investigation of microemulsion system for transdermal delivery of meloxicam", Int. J. Pharm., $321, \quad 117-123$ (2006). doi:10.1016/j. ijpharm.2006.06.021.

8- P. Luger, K. Daneck, W. Engel, G. Trummlitz and K. Wagner, "Structure and physicochemical properties of meloxicam, a new NSAID", Eur. J. Pharm. Sci., 4, 175-187 (1996). doi:10.1016/0928-0987 (95)00046-1.

9- J. W. Bae, M. J. Kim, C. G. Jang and S. Y. Lee, "Determination of meloxicam in human plasma using a HPLC method with UV detection and its application to a pharmacokinetic study", J. Chromatogr. B Anal. Technol. Biomed. Life Sci., 859, 69-73 (2007). doi:10.1016/j.jchromb.2007. 09.004 .

10- H. Trommer and R. H. H. Neubert, "Overcoming the stratum corneum: The modulation of skin penetration. A review", Skin Pharmacol. Physiol., 106-121 (2006). doi:10.1159/000091978.

11- R. H. Müller, K. Mäder and S. Gohla, "Solid lipid nanoparticles (SLN) for controlled drug delivery - A review of the state of the art", Eur. J. Pharm. $\begin{array}{llll}\text { Biopharm., } & 50, \quad 161-177 \text { (2000). }\end{array}$ doi:10.1016/S0939-6411(00)00087-4. 
12- Müller R. H., W. Mehnert, J.-S. Lucks, C. Schwarz, A. Zur Mühlen, H. Meyhers, C. Freitas and D. Rühl, "Solid lipid nanoparticles (SLN): An alternative colloidal carrier system for controlled drug delivery", ibid., 41, 62-69 (1995).

13- A. Zur Mühlen, C. Schwarz and W. Mehnert, "Solid lipid nanoparticles (SLN) for controlled drug delivery - Drug release and release mechanism, ibid., 45, 149-155 (1998). doi:10.1016/S0939-6411(97) 00150-1.

14- K. A. Shah, A. A. Date, M. D. Joshi and V. B. Patravale, "Solid lipid nanoparticles (SLN) of tretinoin: Potential in topical delivery", Int. J. Pharm., 345, 163-171 (2007). doi:10.1016/j.ijpharm.2007. 05.061 .

15- Y. Agrawal, K. C. Petkar and K. K. Sawant, "Development, evaluation and clinical studies of Acitretin loaded nanostructured lipid carriers for topical treatment of psoriasis", ibid., 401, 93-102 (2010). doi:10.1016/j.ijpharm.2010. 09.007.

16- R. H. Müller, M. Radtke and S. A. Wissing, "Solid lipid nanoparticles (SLN) and nanostructured lipid carriers (NLC) in cosmetic and dermatological preparations", Adv. Drug Deliv. Rev., S131-S155 (2002). doi:10.1016/S0169-409X(02) 00118-7.

17- A. Weerheim and M. Ponec, "Determination of stratum corneum lipid profile by tape stripping in combination with high-performance thin-layer chromatography", Arch. Dermatol. Res., 293, 191-199 (2001). doi:10.1007/ s004030100212.

18- W. Mehnert and K. Mäder, "Solid lipid nanoparticles: Production, characterization and applications", Adv. Drug Deliv. Rev., 64, 83-101 (2012). doi:10.1016/j.addr. 2012.09.021.

19- J. P. Jee, S. J. Lim, J. S. Park and C. K. Kim, "Stabilization of all-trans retinol by loading lipophilic antioxidants in solid lipid nanoparticles", Eur. J. Pharm. Biopharm., 63, 134-139 (2006). doi:10.1016/j.ejpb.2005.12.007.
20- V. Teeranachaideekul, R. H. Müller and V. B. Junyaprasert, "Encapsulation of ascorbyl palmitate in nanostructured lipid carriers (NLC)-Effects of formulation parameters on physicochemical stability", Int. J. Pharm., 340, 198-206 (2007). doi:10.1016/j.ijpharm.2007.03.022.

21- E. B. Souto and R. H. Müller, "Investigation of the factors influencing the incorporation of clotrimazole in SLN and NLC prepared by hot high-pressure homogenization", J. Microencapsul., 23, 377-388 (2006). doi:10.1080/ 02652040500435295.

22- R. H. Müller, M. Radtke and S. A. Wissing, "Nanostructured lipid matrices for improved microencapsulation of drugs", Int. J. Pharm., 242, 121-128 (2002). doi:10.1016/S0378-5173(02) 00180-1.

23- B. Gaba, M. Fazil, A. Ali, S. Baboota, J. K. Sahni and J. Ali, "Nanostructured lipid (NLCs) carriers as a bioavailability enhancement tool for oral administration", Drug Deliv., 22, 691-700 (2015). doi:10.3109/10717544.2014.898110.

24- C. Y. Guo, C. F. Yang, Q. L. Li, Q. Tan, Y. W. Xi, W. N. Liu and G. X. Zhai, "Development of a Quercetin-loaded nanostructured lipid carrier formulation for topical delivery", Int. J. Pharm., 430, 292-298 (2012). doi:10.1016/j.ijpharm. 2012.03.042.

25- C. H. Loo, M. Basri, R. Ismail, H. L. N. Lau, B. A. Tejo, M. S. Kanthimathi, H. A. Hassan and Y. M. Choo, "Effect of compositions in nanostructured lipid carriers (NLC) on skin hydration and occlusion", Int. J. Nanomedicine, 8, 1322 (2013). doi:10.2147/IJN.S35648.

26- M. Joshi and V. Patravale, "Nanostructured lipid carrier (NLC) based gel of celecoxib", Int. J. Pharm., 346, 124-132 (2008). doi:10.1016/j.ijpharm. 2007.05.060.

27- C. Puglia, P. Blasi, L. Rizza, A. Schoubben, F. Bonina, C. Rossi and M. Ricci, "Lipid nanoparticles for prolonged topical delivery: An in-vitro and in-vivo investigation", ibid., 357 (2008) 295-304. doi:10.1016/j.ijpharm.2008.01.045. 
28- K. Manjunath and V. Venkateswarlu, "Pharmacokinetics, tissue distribution and bioavailability of nitrendipine solid lipid nanoparticles after intravenous and intraduodenal administration", J. Drug Target., 14, 632-645 (2006). doi:10.1080/10611860600888850.

29- H. Yuan, L. L. Wang, Y. Z. Du, J. You, F. Q. $\mathrm{Hu}$ and $\mathrm{S}$. Zeng, "Preparation and characteristics of nanostructured lipid carriers for control-releasing progesterone by melt-emulsification", Colloids Surfaces B Biointerfaces, 60, 174-179 (2007). doi:10.1016/j.colsurfb.2007. 06.011.

30- H. A. Fathi, A. Allam, M. Elsabahy, G. Fetih and M. El-Badry, "Nanostructured lipid carriers for improved oral delivery and prolonged antihyperlipidemic effect of simvastatin", ibid., 162, 236-245 (2018). doi:10.1016/j.colsurfb.2017.11.064.

31- M. S. García, C. Sánchez-Pedreño, M. I. Albero and J. Marti, "Spectrophotometric methods for determining meloxicam in pharmaceuticals using batch and flowinjection procedures", Eur. J. Pharm. Sci., (2000). doi:10.1016/S0928-0987(99) 00069-X.

32- R. W. Korsmeyer, R. Gurny, E. Doelker, P. Buri and N. A. Peppas, "Mechanisms of solute release from porous hydrophilic polymers", Int. J. Pharm., 15, 25-35 (1983). doi:10.1016/0378-5173(83)900649.

33- M. El-Badry, G. Fetih, D. Fathalla and F. Shakeel, "Transdermal delivery of meloxicam using niosomal hydrogels: Invitro and pharmacodynamic evaluation", Pharm. Dev. Technol., 20, 820-826 (2015). doi:10.3109/10837450.2014. 926919.

34- S. Khurana, N. K. Jain and P. M. S. Bedi, "Development and characterization of a novel controlled release drug delivery system based on nanostructured lipid carriers gel for meloxicam", Life Sci. (2013). doi:10.1016/j.1fs.2013.09.027.
35- Y. Wada, Y. Etoh, A. Ohira, H. Kimata, T. Koide, H. Ishihama and Y. Mizushima, "Percutaneous absorption and antiinflammatory activity of indomethacin in ointment", J. Pharm. Pharmacol., 34, 467-468 (1982). doi:10.1111/j.20427158.1982.tb04763.x.

36- E. Escribano, A. C. Calpena, J. Queralt, R. Obach and J. Doménech, "Assessment of diclofenac permeation with different formulations: Anti-inflammatory study of a selected formula", Eur. J. Pharm. Sci., 19, 203-210 (2003). doi:10.1016/S09280987(03)00103-9.

37- R. M. Khalil, A. Abd-Elbary, M. A. Kassem, M. M. Ghorab and M. Basha, "Nanostructured lipid carriers (NLCs) versus solid lipid nanoparticles (SLNs) for topical delivery of meloxicam", Pharm. Dev. Technol., 19, 304-314 (2014). doi:10.3109/10837450.2013.778872.

38- V. Jenning, A. F. Thünemann and S. H. Gohla, "Characterisation of a novel solid lipid nanoparticle carrier system based on binary mixtures of liquid and solid lipids", Int. J. Pharm., 199, 167-177 (2000). doi:10.1016/S0378-5173(00)00378-1.

39- R. N. Shamma and M. H. Aburahma, "Follicular delivery of spironolactone via nanostructured lipid carriers for management of alopecia", Int. J. Nanomedicine, 9, 5449-5460 (2014). doi:10.2147/IJN.S73010.

40- H. Thakkar, J. Desai and M. Parmar, "Application of Box-Behnken design for optimization of formulation parameters for nanostructured lipid carriers of candesartan cilexetil", Asian J. Pharm., 8, 81 (2014). doi:10.4103/0973-8398. 134921 . 
Bull. Pharm. Sci., Assiut University, Vol. 42, 2019, pp. 51-62.

نشرة العلوم الصيدليسة

\section{تطوير وتوصيف حوامل دهنيه متتاهيه الصغر لتوصيل

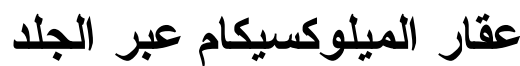

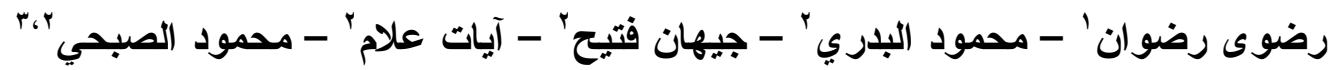

'مركز أسيوط الدولى لأدوية النانو ، مستشفى الراجحي الجامعي للكبد ، جامعة أسيوط ، أسيوط ، مصر ،

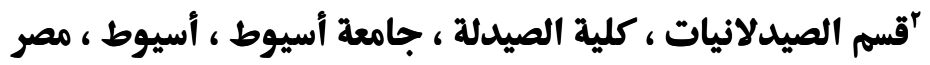

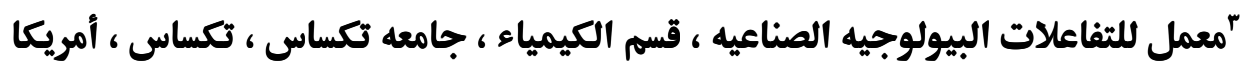

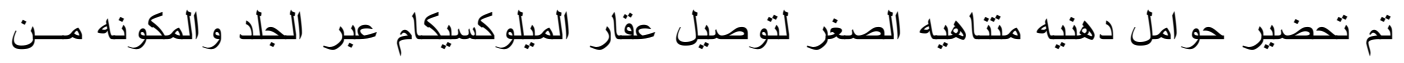

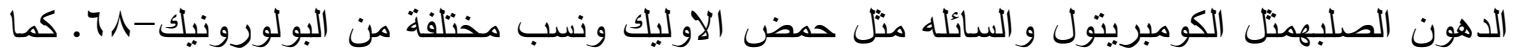

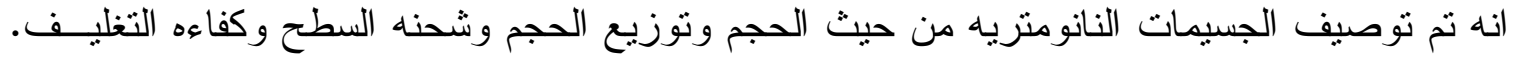

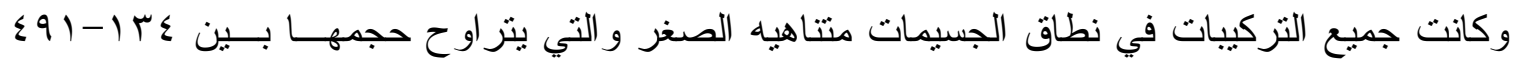





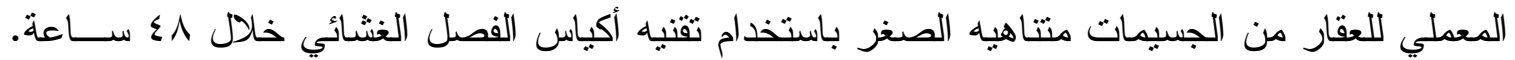



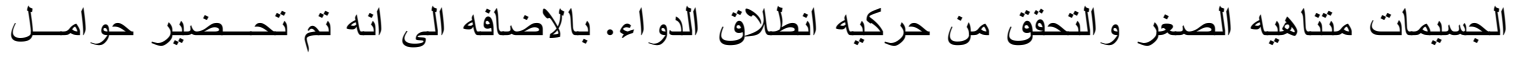

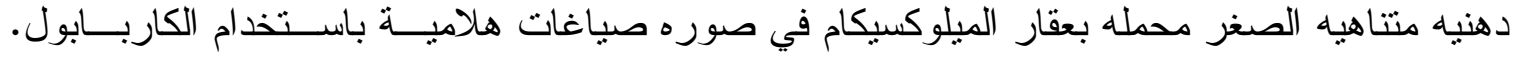

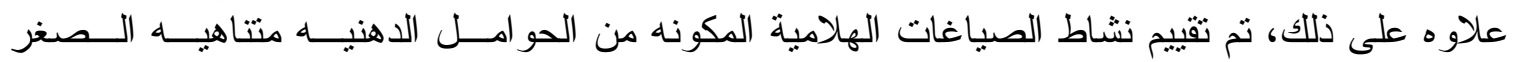

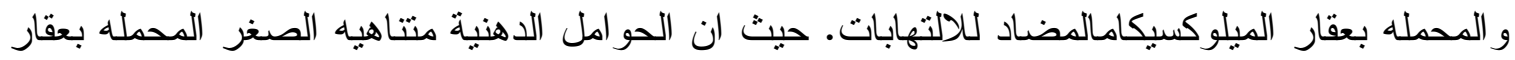

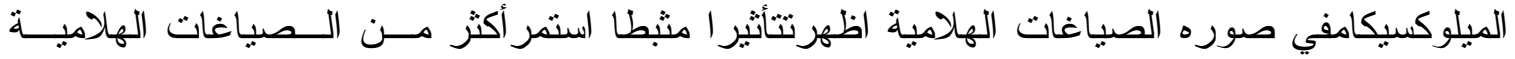
المكونه من عقار الميلوكسيكام الحر ــ واخير ا تم تقييم سمية تلك الصياغات الهيت الهلاميةعن طريق دراسات نسيجية مرضية. 